\title{
ORIGINAL RESEARCH \\ A Qualitative Study on Nurses' Experiences of Reporting Patient Safety Incidents in East Nusa Tenggara, Indonesia
}

\author{
Petrus Kanisius Siga Tage ${ }^{1}$, Appolonaris T. Berkanis ${ }^{1}$, Yasinta Betan ${ }^{1}$, Armi Elisabet Batseba Pinis ${ }^{2}$ \\ ${ }^{1}$ Department of Nursing, Health Sciences Faculty, Universitas Citra Bangsa, East Nusa Tenggara, Indonesia \\ ${ }^{2}$ Prof. Dr. W. Z. Johannes Hospital, East Nusa Tenggara, Indonesia
}

\begin{tabular}{l} 
Article Info \\
\hline Article History: \\
Received: 14 May 2021 \\
Revised: 18 November 2021 \\
Accepted: 23 November 2021 \\
Online: 27 December 2021 \\
Keywords: \\
Incident reporting; nurses; patient \\
safety; qualitative research \\
Corresponding Author: \\
Petrus Kanisius Siga Tage \\
Department of Nursing, Health \\
Sciences Faculty, Universitas Citra \\
Bangsa, East Nusa Tenggara, \\
Indonesia \\
Email: \\
petruskanisiussigatage@ucb.ac.id
\end{tabular}

petruskanisiussigatage@ucb.ac.id

\begin{abstract}
Background: Reporting patient safety incidents is important to improve patient safety and quality of care. Barriers to report patient safety incidents in nursing may occur due to lack of knowledge and unscheduled as well as low reporting rates. Unfortunately, nurses' experiences in reporting patient safety incidents have not been comprehensively reviewed.

Purpose: The purpose of this study was to explore nurses' experiences of reporting patient safety incidents in East Nusa Tenggara, Indonesia.

Methods: A descriptive phenomenological approach was used to identify, analyze and describe the experiences of 15 nurses in reporting patient safety incidents. Nurses having worked for more than two years, not on leave, not being infected with COVID-19 in the last 14 days, and not having a structural position were purposively recruited. Data were collected using in-depth interviews and voice recordings. The collected data were then transcribed verbatim, and thematic analysis was applied for data analysis.

Results: Four main themes were found in this study, which included: (1) Priority and responsibility for services, (2) Barriers to incident reporting, (3) Learning for nurses, and (4) Support for nurses.

Conclusion: The nurses experience of in reporting safety incidents is still constrained by several obstacles. It is hoped that health care organizations need to provide appropriate strategies to enhance the safety incident reporting efforts made by nurses. Based on the research findings, it is recommended that health service organizations disseminate the use of safety incident reporting forms and assist nursing managers to their subordinates by conducting supervision and motivation related to incident reporting on a scheduled and continuous basis.
\end{abstract}

How to cite: Tage, P. K. S., Berkanis, A. T., Betan, Y., \& Pinis, A. E. B. (2021). A qualitative study on nurses' experiences in reporting patient safety incidents in East Nusa Tenggara, Indonesia. Nurse Media Journal of Nursing, 11(3), 359-369. https://doi.org/10.14710/nmjn.v11i3.38400

\section{Introduction}

Today, the progress and complexity of health care have led to a growing demand for quality and safe forms of health care services for patients. The high mortality and morbidity associated with health care errors show the importance of improving patient safety in health care units (Amiri et al., 2018). Nurses have an important role to play in improving patient safety.

The nursing care process provides opportunities for nurses to be close to patients and gives them more time with patients. The continuous interaction process between nurses and patients risks causing injury to patients (Amaniyan et al., 2020). When an injury occurs to a patient, nurses need to report to identify and correct errors that threaten patient safety. The data obtained from incident reports can be used to understand the scale and hazards arising from services and as a form of learning to reduce ongoing risks (World Health Organization, 2020).

Patient safety incidents reporting should make a major contribution to revealing the risk of injury posed by nurses. A good safety incident reporting process should pay attention to ways to identify risks, clear risk priorities, methods for analyzing and investigating sources of risk, good communication among staff, and follow-up on problems that arise (World Health Organization, 2020). The patient safety reporting process carried out by nurses is still not optimally carried out due to obstacles with sharing reasons such as the reluctance of nurses to report for fear of punishment, lack of knowledge, lack of time, excessive workload (Alves et al., 2019), absence of role models, lack of response from supervisors/leaders, and the belief that reporting is not part of 
a nurse's job (Lee et al., 2018). Another study illustrates that demographic factors such as gender and marital status can affect patient reporting safety incidents (Jember et al., 2018).

Since 2006, health care facilities in Indonesia have implemented a safety incident reporting system; however, its implementation has not been maximally implemented due to a lack of understanding and a lot of confusion among Indonesian health workers (Dhamanti et al., 2019). In addition, the number of patient safety reports nationally is still low. During 2015-2019, the number of patient safety incident reports was 12\% (Indonesian Hospital Association, 2020). Another study conducted by Tristantia (2018) shows that the incident reporting system in Indonesia is still not timely. Reporting patient safety incidents that are not carried out properly can have an impact on decreasing the quality of patient care and patient safety (Gqaleni \& Bhengu, 2020), medication errors (Zarea et al., 2018), and death for patients (Martin et al., 2019).

Various problems related to reporting safety incidents that occur in nursing services require efforts to identify incident reporting problems from the perspective of nurses to understand the conditions experienced by nurses regarding reporting as a whole. In Indonesia, the study of reporting safety incidents by nurses is still limited and has never touched the comprehensive experience of nurses in reporting safety incidents. Existing studies are limited to looking at cultural and practical barriers (Dhamanti et al., 2020; Hewitt et al., 2017), the influence of the work environment (Faridah et al., 2021), the impact of leadership and nurses' perceptions (Wanda et al., 2020) and the attitude of nurses in reporting safety incidents (Kusumawati et al., 2019). Therefore, this study was conducted to explore nurses' experience in reporting safety incidents, so that it could be an input for managers and health care organizations to determine appropriate actions for nurses in improving patient safety reporting.

\section{Methods}

\subsection{Research design}

The present study employed a descriptive phenomenological approach. Descriptive phenomenology aims to shape the understanding of life experiences while emphasizing the richness, breadth, and depth of those experiences (Streubert \& Carpenter, 2011).

\subsection{Setting and participants}

This study involved two hospitals in East Nusa Tenggara, Indonesia and was conducted from September to December 2020. The first hospital is a type B general education hospital with a plenary level of accreditation status. In contrast, the second is a type $\mathrm{C}$ police hospital with a major level of accreditation status. The choice of hospital was due to the low level of reporting of safety incidents by nurses.

Recruitment of the participants began with an approach to the unit manager to obtain data on nurses that matched the inclusion criteria, such as (1) Nurses with more than two years of service, (2) Nurses who were not on leave, (3) Nurses who had not been declared in the last 14 days infected with COVID-19, (4) Nurses who did not have a structural positions. A purposive sampling technique was used to recruit these participants. In total, participants involved in the study were 15 nurses.

\subsection{Data collection}

After getting the name of the potential participants, the researcher took a personal approach to ask for approval. When participants agreed to be involved in the study, potential participants were asked to provide their telephone numbers, and the researcher contacted them to determine the interview process. After the list of potential participants with telephone numbers was collected, the researchers contacted them by telephone and made an appointment with the participants for an interview session.

The interview process was carried out at the hospital where the nurse worked during working hours. The interview was conducted for approximately 60 minutes face to face with health protocols during the COVID-19 pandemic, such as using two-layer masks, maintaining a distance of two meters, not making direct physical contact, disinfecting the interview room, and before starting the interview, participants and researchers washed their hands thoroughly-hand rub. In this study, in-depth interviews in the form of semi-structured interviews for each participant were conducted using the interview guidelines (Table 1). During the interview, field notes were written in response to each condition indicated by the participants. The researcher tried to be as objective 
as possible in dealing with participant statements by not including the researcher's opinion and trying to drown in the phenomena expressed by the participants. Data saturation was achieved through in-depth interviews with participants so that no new information was obtained from each participant. Also, participants' privacy and confidentiality were maintained during the interview by submitting a research approval letter, asking permission to record the interview audio, ensuring that the interview room was away from crowds, and the researcher only used the interview results.

Table 1. Interview question guidelines

\begin{tabular}{ll}
\hline & \multicolumn{1}{c}{ Interview Questions } \\
\hline - & What do you know about reporting patient safety incidents? \\
- & How do you report patient safety incidents? \\
- & What is your motivation in reporting patient safety incidents? \\
- & Is the patient safety incident reporting activity a burden for you, and what is the \\
& solution? \\
- & How do your colleagues, other healthcare teams, and leaders respond when you \\
- & What probortient safety incidents? \\
& incident? \\
- & Are there any other experiences you would like to share with patient safety \\
& incident reporting?
\end{tabular}

\subsection{Data analysis}

The data were analyzed using a thematic analysis. A thematic analysis approach is needed to identify, analyze, organize, describe, and report on the themes found in the data set from the interview results (Braun \& Clarke, 2006). The thematic analysis process used the approach offered by (Nowell et al., 2017) with the following guidelines: (1) Know data well; researchers read the entire data set of nurses' experiences before starting coding to understand the depth and breadth of experiences expressed by nurses; (2) Creating initial codes; this was conducted by two researchers manually by using a template to simplify specific characteristics of the nurses' experience data by being coded and organized into different code lists; (3) Searching for themes; this was done inductively; themes were identified based on the experience data of the nurses themselves and have little relation to the specific questions asked to the participants; (4) Reviewing the themes; to assess whether the theme regarding the nurse's experience is reasonably coherent with existing supporting data; (5) Determine and name the theme; modify and refine the definitions of emerging themes; four researchers conducted discussions and reviewed the nurse's experience data three times, and (6) Producing the report: before writing the report, the researcher sent the analysis to the participants for their feedback through the member checking process to determine the unity between respondents' views and the researchers' representation.

\subsection{Trustworthiness/rigor of the study}

Rigor in qualitative research is seen as the strength of the research design and the suitability of the method for answering the objective questions posed by the researcher (Cypress, 2017). In this study, the researchers conducted several strategies to ensure rigor based on the guidelines from de Chesnay (2015) and Forero et al. (2018), as illustrated in Table 2.

\subsection{Ethical considerations}

Ethical approval was obtained from the Ethical Committee of the Health Polytechnic of the Ministry of Health, Kupang, Indonesia (Reference Number: LB 02.03/1/0049/2020). Permission from and the hospital director was obtained before the data collection process. All prospective participants were given a research information sheet regarding the research objectives, the role of the researcher, data confidentiality, the right to withdraw, and the length of the interview. Participants' approval marks were obtained before the interview was conducted. Consent was obtained directly from the nurses involved in the study. 
Table 2. Strategies to improve the rigor of the study

\begin{tabular}{|c|c|c|}
\hline Criteria & Purpose & Application \\
\hline Credibility & $\begin{array}{l}\text { To build confidence that } \\
\text { research results are } \\
\text { correct and can be } \\
\text { trusted }\end{array}$ & 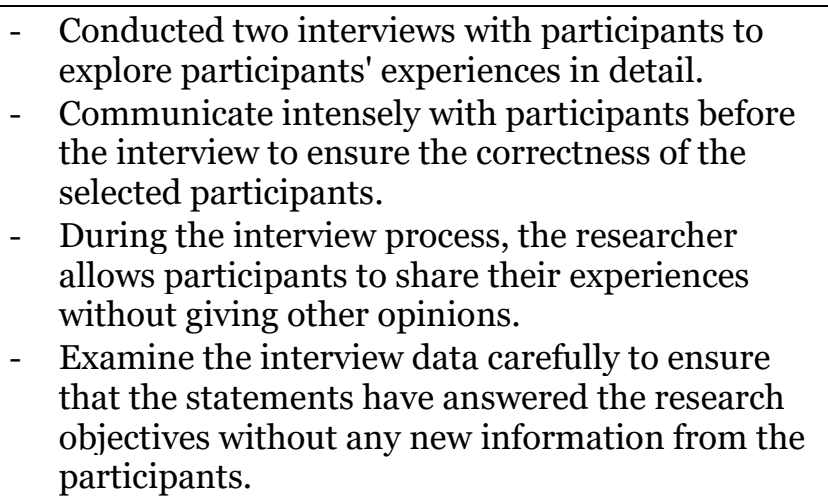 \\
\hline Transferability & $\begin{array}{l}\text { Knowing the extent to } \\
\text { which results can be } \\
\text { generalized or } \\
\text { transferred to other } \\
\text { contexts or studies }\end{array}$ & $\begin{array}{l}\text { - Use the purposive sampling technique in this } \\
\text { study as a technique to recruit participants. } \\
\text { - } \quad \text { Background of research problems related to } \\
\text { previously published studies. } \\
\text { - } \quad \text { Use descriptive phenomenology methodology as a } \\
\text { type of qualitative study. } \\
\text { - There are } 15 \text { participants involved with different } \\
\text { demographic characteristics in the study as a } \\
\text { sufficient condition in qualitative research. }\end{array}$ \\
\hline Dependability & $\begin{array}{l}\text { Ensures research } \\
\text { findings are repeatable if } \\
\text { investigations occur in } \\
\text { the same group of } \\
\text { participants and } \\
\text { contexts. }\end{array}$ & $\begin{array}{l}\text { - Make a detailed draft of the research protocol in } \\
\text { the study. } \\
\text { - } \text { Re-checking the accuracy of data coding by two } \\
\text { researchers. }\end{array}$ \\
\hline Confirmability & $\begin{array}{l}\text { Increase the confidence } \\
\text { that research results can } \\
\text { be confirmed or by } \\
\text { different researchers }\end{array}$ & $\begin{array}{l}\text { - Triangulation of data using investigator } \\
\text { triangulation, which includes the use of several } \\
\text { researchers during the interview process. } \\
\text { - Make a diary related to research developments by } \\
\text { determining the topic, methodology, data } \\
\text { analysis, interpretation of results, and presenting } \\
\text { conclusions. }\end{array}$ \\
\hline
\end{tabular}

\section{Results}

3.1 Characteristics of participants

Nurse participants involved in this study were 15 nurses who agreed to share their experiences of reporting patient safety incidents. The majority of the participants were female (80\%), graduates of Diploma 3 of nursing (66.7\%), and hard work experiences of 1-5 years (40\%), and attended patient safety training for one time (80\%). In detail, the participant background is shown in Table 3.

\subsection{Themes emerged}

In this study, four themes were developed. The first theme was the priority and responsibility for services. This theme illustrates that nurses see safety incident reporting as a priority in service, a service responsibility, an effort to avoid actions that harm patients. There need to be action guidelines for nurses. The second theme was the barriers to incident reporting. It consisted of three sub-themes: low staff awareness to carry out safety reporting, lack of staff commitment, and feelings of fear, shame, and discomfort. The third was learning for nurses. This theme describes that nurses have gained new knowledge when reporting safety incidents and can learn to see mistakes to improve. The last was support for nurses. The main picture of this theme is that nurses feel there is support from the organization and the availability of rewards for nurses when reporting incidents. 
Table 3. Characteristics of participants $(n=15)$

\begin{tabular}{lcc}
\hline Characteristics & $\mathrm{f}$ & $\%$ \\
\hline Gender & 3 & 20 \\
$\quad$ Male & 12 & 80 \\
$\quad$ Female & & \\
Education & 10 & 66.7 \\
$\quad$ Diploma 3 of nursing & 5 & 33.3 \\
$\quad$ Bachelor of nursing & & \\
Work experience & 6 & 40 \\
$\quad$ 1-5 years & 4 & 26.7 \\
6-10 years & 5 & 33.3 \\
$\quad$ 11 years & & \\
Patient safety training & 12 & 80 \\
1 time & 2 & 13.3 \\
2 times & 1 & 6.7 \\
$\quad>2$ times & & \\
\hline
\end{tabular}

\subsubsection{Priority and responsibility for services}

The theme of priority safety and service responsibility illustrates the nurses' perceptions of the importance of reporting patient safety incidents. Several participants said that they viewed the reporting of safety incidents as a priority in the services they provide.

"Patient safety reporting is something we must do and prioritize in nursing services. After reporting, we can avoid the same mistakes. If we report it, there will be an evaluation and improvement of nursing services" (P1)

In addition, the nurse perceived that reporting patient safety incidents was aimed at protecting patients; nurses should understand it as a service responsibility.

"If we want patients to remain safe from the dangers of our care, nurses must see that incident reporting is the knowledge that all nurses should have. Nurses must be well-informed about what needs to be reported. In addition, reporting the incident is mandatory; all minor incidents must be reported" (P8)

Efforts to protect patients, according to the nurses, are not limited to incident reporting. The critical thing to do is to ensure that the patient remains safe. The nurse said that it should start with efforts to avoid actions that harm the patient.

"It is not enough just to report incidents; the most important thing is that nurses always try to avoid the dangers that arise such as advising patients to wear loose clothing, installing bed protectors, and periodically checking the patient's identity bracelet.” $\left(\mathrm{P}_{7}\right)$

Nurses also viewed that to support patient safety efforts in a comprehensive manner that can be implemented in the hospital, the action guidelines should be available as a guide for nurses.

"In ensuring that patients remain safe, we must have safety standards such as prevention of the risk of falling, prevention of infection, use of high alert drugs. This guideline must be in the room and updated according to the development of existing science." (P9)

\subsubsection{Barriers to incident reporting}

This theme consists of several sub-themes that describe the barriers felt by nurses related to patient safety incidents reporting. 


\subsubsection{Low staff awareness}

According to the participants, although the efforts to implement patient safety have been done, its implementation is not yet optimal. Some participants stated that staff awareness was still low to carry out safety reporting.

"There are various kinds of people with attitudes who realize that this is very important, while others do not care. Usually, those who have low awareness will ignore any incidents; they still think that it is a normal thing." (P14)

Other participants also expressed low concern for the issue of reporting patient safety incidents. P12 stated: "I see on many occasions, my co-workers sometimes don't care, especially if there is an error, but the patient is not injured, so they consider it normal."

\subsubsection{Lack of commitment}

Different participants said that they found that there was no common understanding and commitment among other health workers regarding efforts to implement patient safety incident reporting.

"Laboratory personnel are often ignorant or do not respond appropriately. When we send specimens for inspection, they often forget, and we are forced to resend specimens. They did not report this mistake as an incident." ( $\left.\mathrm{P}_{4}\right)$

One participant (P9) said that the desire to report incidents as a form of work commitment was still low; he stated: "Among my colleagues, I see that commitment is still low, always as a team leader I remind my members during shifts to report incidents, but there are still those who do not report."

\subsubsection{Feel scared, embarrassed, and uncomfortable}

Another barrier expressed by participants in this study regarding patient safety incident reporting activities was that nurses felt afraid, embarrassed, and uncomfortable with their colleagues when they wanted to report. The pressure felt was expressed by several participants.

"I feel embarrassed to report an incident that happened, either by myself or by a friend, it's like exposing ourselves, stripping ourselves apart, and it feels uncomfortable if we want to report such mistakes." ( $\left.\mathrm{P}_{3}\right)$

The emotional problems felt by nurses when they were going to report patient safety incidents were also conveyed differently by one of the participants; P6 stated: "What I feel when I want to report a safety incident is a bad reaction from my supervisor or senior nurses, they are usually angry, although in the end they also advise me, it scares me."

\subsubsection{Learning for nurses}

The importance of reporting patient safety incidents is the beginning of the learning process to prevent the same incident from happening again. Reporting was considered very useful for reducing incidents and improving the quality of patient safety services. By reporting patient safety incidents, nurses gain new knowledge in services. Some participants expressed knowledge about the benefits of patient safety incidents reporting.

"Reporting allows us to be able to find out the cause of the problem so that it can be resolved and repaired, that way our services are getting better, patients feel satisfied so that in the future the number of patient visits increases and the hospital benefits." (P6)

Other participants revealed that through good reporting, nurses could also learn to find mistakes and make improvements. P15 expressed: "There is new knowledge that I get when I make a report. I can find out the wrong action so that in the future I can provide good service to patients." 


\subsubsection{Support for nurses}

Hospitals have an essential role in reporting patient safety incidents. The hospital as an organization in the patient safety program always reminds, supports, and motivates reporting. Participants expressed their experiences as follows:

"The leaders always remind us to make a safety incident report even though the incident is small, besides that they do not scold us if there is an incident that we report, but we are still reminded always to be vigilant." (P11)

Different participants explain that if the nurse reports an incident, the hospital will count the actions taken as performance points so that the nurse gets rewarded for their action.

"If we make a report about problems we do or encounter while caring for patients, we will get five points to increase our performance credit, the more points we get, the better the performance, and we will get additional wages in the form of a performance allowance." $\left(\mathrm{P}_{7}\right)$

\section{Discussion}

This study aimed to explore the nurses' experiences of patient safety incident reporting. From the data collection and analysis results, four themes were found: (1) Priority and responsibility for services, (2) Barriers to incident reporting, (3) Learning for nurses, (4) Support for nurses.

\subsection{Priority and responsibility for services}

In this study, the participants viewed that reporting patient safety incidents was the responsibility of the services carried out by nurses. A similar view was found in a previous study which explains that nurses feel the need to take responsibility for their mistakes and emphasizes the importance of collecting data about errors for preventive action in the future (Vaismoradi, Vizcaya-Moreno, et al., 2020). Nurses are responsible for any actions and consequences, whether therapeutic or harmful (Tan et al., 2020).

Reporting efforts as a form of responsibility alone is not enough. Therefore, serious efforts are needed to avoid actions that endanger patients as a priority in service. In line with these findings, a previous study reported that the factors determining patient safety must begin with efforts to avoid actions that harm patients, including preventing medical errors and other adverse events (Vaismoradi, Tella, et al., 2020). Nurses must actively build moral awareness and commitment to minimizing actions that harm patients (Kleemola et al., 2020; Younas et al., 2020).

Nurses in this study also viewed that reporting patient safety incidents could be appropriately implemented; so, nurses must be equipped with knowledge and work according to applicable standard procedures. A previous study about the nurses' need for safety knowledge (di Simone et al., 2018) explained that the experience and skills of developing patient safety-related science are essential to forming the correct behavior of a nurse in preventing errors when providing services to patients. Standard protocols to reduce the risk of errors also need to be developed significantly to minimize negligence. Everyone involved in the process must develop standard patient safety procedures and implement them in inpatient care (Papadakis et al., 2019).

\subsection{Barriers to incident reporting}

Barriers to reporting safety incidents were identified in this study. The nurses explained that staff awareness was still low regarding incident reporting. This finding is in line with a study conducted by Khalil and Lee (2018) who identified problems surrounding reporting medication errors in nursing. The result indicated that nurses' awareness is still low in reporting safety incidents. Nurses need to be reminded to do reporting. The supportive work environment affects nurses' willingness to voluntarily report incidents (Chen et al., 2018). Nursing managers need to continuously create a work environment conducive to nurses and remind them to make reports in an incident that endangers the patient.

This study found that the obstacle felt by nurses was the absence of commitment from other professions to support patient safety incident reporting efforts. Joint commitment among health workers for reporting safety incidents is an important thing that must be built-in in patient safety efforts. Commitment is a significant predictor of all existing safety outcome measures in 
healthcare facilities (Kuosmanen et al., 2019; Mashi et al., 2018). All health professionals should understand patient safety reports and cover the entire spectrum of care available in the health service. Each profession has a responsibility to report incidents that include various events from their immediate environment.

Another finding in this study showed that nurses felt that patient safety incident reporting activities make them afraid, embarrassed, and uncomfortable with their colleagues when they want to do reporting. A study conducted by Lee et al. (2019) related to barriers to reporting safety incidents in Korea among 16 health workers (six doctors, eight nurses, and two pharmacists) experiencing patient safety incidents, the same thing as found in this study, showed that health workers felt embarrassed to report safety incidents due to experiencing various emotional reactions such as shame, guilt, and depression, as well as behavioral changes such as insomnia, avoidance, and consideration of career changes. Another study describes the embarrassment because nurses think they have made a mistake and regret it for harming health care professionals and institutions (van Gerven et al., 2016). The psychological condition experienced by nurses must be taken seriously; assistance needs to be done to report every incident without any pressure.

\subsection{Learning for nurses}

By reporting patient safety incidents, nurses explained that they are gaining new knowledge that supports their practice. The findings of this study are in line with a study by Rashed and Hamdan (2019), where it was explained that nurses viewed incident reporting as something positive because they can learn from mistakes and are more motivated to report in the future. In particular, incident reporting was assessed as a catalyst to change the way of thinking about risk, increase knowledge and awareness of the good practice, and highlight the need for resources that can shape safety culture. Safety incidents are not isolated but are influenced by a more significant problem (Leistikow et al., 2017). Therefore, health care providers, including nurses, need to learn how to solve the infinite variable of safety problems by studying and designing corrective actions following available science and regulations.

After learning from the problems that arise, the nurse sees that incident reporting is a means to improve service. Adverse incident reporting is a cornerstone of clinical governance and supports health care improvement. The resulted information can serve as a guide for service improvement. A study that analyses the impact of incident reporting on service improvements carried out by Carlfjord et al. (2018) shows that reporting has a significant effect on improving patient safety governance, which helps put patient safety at the top of the agenda for health care practices and changes in a non-blaming reporting culture among health workers.

\subsection{Support for nurses}

The findings of this study showed that patient safety reporting has the support of leadership. Previous research found that organizational strength has an important influence on hospital patient safety efforts through management support for safety, promotion of patient safety measures by supervisors, and feedback or communication about errors (Ali et al., 2018). Attention from the organization can increase reporting awareness to reduce the number of mistakes. Organizations need to establish a sound system to ensure patient safety is a priority service provided to patients.

Nurses in this study also reported about the attention of organizations to reporting safety incident activities through increasing wages. In a safety culture, people are rewarded for improving safety, either as individuals or team members. A study conducted by Ahmed and Faheem (2021) showed that incentives affect motivation to carry out safety reporting but are not applied in the long term because salary to improve safety culture is only effective in the short term. The organization needs to establish an appropriate approach to enhance the continuous reporting of safety incidents over a long period. Furthermore, a study conducted by Hennessy et al. (2018) concluded that in promoting patient safety, hospitals need to improve their knowledge, skills, and attitudes towards a sustainable patient safety culture through training programs, benchmarking, institutionalization and accreditation. 


\section{Implications and limitations}

This study provides interesting findings that are important for understanding the phenomenon of nurses in reporting patient safety incidents. Given nurses' perceived barriers in reporting safety incidents, nursing managers need to provide effective guidance for their subordinates to openly and actively report patient safety incidents. The results of this study provide input for health care organizations to develop a conducive work climate to support nurses in reporting patient safety incidents.

This research has limitations. Because this study reflects the perspective of nurses in one particular area at a time, it may not be representative of another broader group. Thus, future research can be carried out to explore the experiences of nurse groups from a wider population.

\section{Conclusion}

This study produces an essential theme regarding the experience of Indonesian nurses in reporting safety incidents. Nurses see that safety incidents are a responsibility they must have and become a priority in service to patients. The nurse also recognizes that incident reporting can be a good learning tool to reduce similar errors in the future. Even though nurses' positive reports, they also felt that there were still obstacles in implementing safety incident reporting efforts that could threaten patient safety management. The provision of performance incentives for incident reporting and motivation from the leadership that has been done needs to be maintained, however as a long-term strategy, and service organizations need to think about the right approach to create a safety culture in the hospital through the development of appropriate regulations.

\section{Acknowledgment}

The authors would like to thank the participants of this study who shared their time and experiences.

\section{Author's contribution}

PKST: study design, conceptualization, data collection, data analysis, manuscript writing; ATB: study design, manuscript writing, data collection; YB: study design, data analysis, data collection; AEBP: study design, data collection, data analysis.

\section{Conflict of interest}

None

\section{References}

Ahmed, I., \& Faheem, A. (2021). How effectively safety incentives work? A randomized experimental investigation. Safety and Health at Work, 12(1), 20-27. https://doi.org/10.1016/j.shaw.2020.08.001

Ali, H., Ibrahem, S. Z., al Mudaf, B., al Fadalah, T., Jamal, D., \& El-Jardali, F. (2018). Baseline assessment of patient safety culture in public hospitals in Kuwait. BMC Health Services Research, 18(1), 1-12. https://doi.org/10.1186/s12913-018-2960-x

Alves, M., de Carvalho, D. S., \& de Albuquerque, G. S. C. (2019). Barriers to patient safety incident reporting by Brazilian health professionals: An integrative review. Ciencia e Saude Coletiva, 24(8), 2895-2908). https://doi.org/10.1590/1413-81232018248.23912017

Amaniyan, S., Faldaas, B. O., Logan, P. A., \& Vaismoradi, M. (2020). Learning from patient safety incidents in the emergency department: A systematic review. Journal of Emergency Medicine, 58(2), 234-244. https://doi.org/10.1016/j.jemermed.2019.11.015

Amiri, M., Khademian, Z., \& Nikandish, R. (2018). The effect of nurse empowerment educational program on patient safety culture: A randomized controlled trial. BMC Medical Education, 18(1), 1-8. https://doi.org/10.1186/s12909-018-1255-6

Braun, V., \& Clarke, V. (2006). Using thematic analysis in psychology. Qualitative Research in Psychology, 3(2), 77-101. https://doi.org/10.1191/1478088706qpo63oa

Carlfjord, S., Öhn, A., \& Gunnarsson, A. (2018). Experiences from ten years of incident reporting in health care: A qualitative study among department managers and coordinators. $B M C$ Health Services Research, 18(1), 1-9. https://doi.org/10.1186/s12913-018-2876-5 
Chen, L. C., Wang, L. H., Redley, B., Hsieh, Y. H., Chu, T. L., \& Han, C. Y. (2018). A study on the reporting intention of medical incidents: A nursing perspective. Clinical Nursing Research, 27(5), 560-578. https://doi.org/10.1177/1054773817692179

Cypress, B. S. (2017). Rigor or reliability and validity in qualitative research: perspectives, strategies, reconceptualization, and recommendations. Dimensions of Critical Care Nursing, 36(4), 253-263. https://doi.org/10.1097/DCC.0000000000000253

de Chesnay, M. (2015). Nursing research using phenomenology: Qualitative designs and methods in nursing (M. de Chesnay, Ed.). Springer Publishing Company.

Dhamanti, I., Leggat, S., \& Barraclough, S. (2020). Practical and cultural barriers to reporting incidents among health workers in Indonesian public hospitals. Journal of Multidisciplinary Healthcare, 13, 351-359. https://doi.org/10.2147/JMDH.S240124

di Simone, E., Giannetta, N., Auddino, F., Cicotto, A., Grilli, D., \& di Muzio, M. (2018). Medication errors in the emergency department: Knowledge, attitude, behavior, and training needs of nurses. Indian Journal of Critical Care Medicine, 22(5), 346-352. https://doi.org/10.4103/ijccm.IJCCM_63_18

Faridah, I., Setyowati, S., Lestari, F., \& Hariyati, R. T. S. (2021). The correlation between work environment and patient safety in a general hospital in Indonesia. Enfermería Clínica, 31, S220-S224. https://doi.org/10.1016/J.ENFCLI.2020.12.026

Forero, R., Nahidi, S., de Costa, J., Mohsin, M., Fitzgerald, G., Gibson, N., McCarthy, S., \& Aboagye-Sarfo, P. (2018). Application of four dimension criteria to assess rigour of qualitative research in emergency medicine. BMC Health Services Research, 18(1), 120. https://doi.org/10.1186/s12913-018-2915-2

Gqaleni, T. M., \& Bhengu, B. R. (2020). Analysis of patient safety incident reporting system as an indicator of quality nursing in critical care units in KwaZulu-Natal, South Africa. Health SA Gesondheid, 25. https://doi.org/10.4102/HSAG.V25Io.1263

Hennessy, K., Abe, C., \& Tuppal, C. P. (2018). Patient safety goals' level of attainment in selected tertiary hospitals in Manila, Philippines: A preliminary study. Nurse Media Journal of Nursing, 8(1), 1-12. https://doi.org/10.14710/NMJN.V8I1.18536

Hewitt, T., Chreim, S., \& Forster, A. (2017). Sociocultural factors influencing incident reporting among physicians and nurses: Understanding frames underlying self and peer reporting $\begin{array}{lllll}\text { practices. Journal of Patient } & \text { Safety, 13(3), 129-137. }\end{array}$ https://doi.org/10.1097/PTS.oooooooooooo0130

Indonesian Hospital Association. (2020). Patient safety incident reporting system. Indonesian Hospital Association.

Jember, A., Hailu, M., Messele, A., Demeke, T., \& Hassen, M. (2018). Proportion of medication error reporting and associated factors among nurses: A cross sectional study. BMC Nursing, 17(1), 1-8. https://doi.org/10.1186/S12912-018-0280-4

Khalil, H., \& Lee, S. (2018). Medication safety challenges in primary care: Nurses' perspective. Journal of Clinical Nursing, 27(9-10), 2072-2082. https://doi.org/10.1111/JOCN.14353

Kleemola, E., Leino-Kilpi, H., \& Numminen, O. (2020). Care situations demanding moral courage: Content analysis of nurses' experiences. Nursing Ethics, 27(3), 714-725. https://doi.org/10.1177/0969733019897780

Kuosmanen, A., Tiihonen, J., Repo-Tiihonen, E., Eronen, M., \& Turunen, H. (2019). Changes in patient safety culture: A patient safety intervention for finnish forensic psychiatric hospital staff. Journal of Nursing Management, 27(4), 848-857. https://doi.org/10.1111/JONM.12760

Kusumawati, A. S., Handiyani, H., \& Rachmi, S. F. (2019). Patient safety culture and nurses' attitude on incident reporting in Indonesia. Enfermería Clínica, 29, 47-52. https://doi.org/10.1016/J.ENFCLI.2019.04.007

Lee, W., Pyo, J., Jang, S. G., Choi, J. E., \& Ock, M. (2019). Experiences and responses of second victims of patient safety incidents in Korea: A qualitative study. BMC Health Services Research, 19(1), 1-12. https://doi.org/10.1186/s12913-019-3936-1

Leistikow, I., Mulder, S., Vesseur, J., \& Robben, P. (2017). Learning from incidents in healthcare: The journey, not the arrival, matters. BMJ Quality and Safety, 26(3), 252-256. https://doi.org/10.1136/bmjqs-2015-004853 
Martin, G., Ghafur, S., Cingolani, I., Symons, J., King, D., Arora, S., \& Darzi, A. (2019). The effects and preventability of 2627 patient safety incidents related to health information technology failures: A retrospective analysis of 10 years of incident reporting in England and Wales. The Lancet Digital Health, 1(3), e127-e135. https://doi.org/10.1016/S2589-7500(19)30057-3

Mashi, M. S., Subramaniam, C., \& Johari, J. (2018). The effect of management commitment to safety, and safety communication and feedback on safety behavior of nurses: The moderating role of consideration of future safety consequences. The International Journal of Human Resource Management, 31(20), 2565-2594. https://doi.org/10.1080/09585192.2018.1454491

Nowell, L. S., Norris, J. M., White, D. E., \& Moules, N. J. (2017). Thematic analysis: Striving to meet the trustworthiness criteria. International Journal of Qualitative Methods, 16(1). https://doi.org/10.1177/1609406917733847

Papadakis, M., Meiwandi, A., \& Grzybowski, A. (2019). The WHO safer surgery checklist time out procedure revisited: Strategies to optimise compliance and safety. International Journal of Surgery, 69, 19-22. https://doi.org/10.1016/J.IJSU.2019.07.006

Rashed, A., \& Hamdan, M. (2019). Physicians' and nurses' perceptions of and attitudes toward incident reporting in Palestinian hospitals. Journal of Patient Safety, 15(3), 212-217. https://doi.org/10.1097/PTS.0000000000000218

Streubert, J. H., \& Carpenter, D. R. (2011). Qualitative research in nursing advancing the humanistic imperative (5th ed.). Lippincott Williams \& Wilkins.

Tan, J. J. M., Cheng, M. T. M., Hassan, N. B., He, H., \& Wang, W. (2020). Nurses' perception and experiences towards medical device related pressure injuries: A qualitative study. Journal of Clinical Nursing, 29(13-14), 2455-2465. https://doi.org/10.1111/JOCN.15262

Tristantia, A. D. (2018). Evaluasi sistem pelaporan insiden keselamatan pasien di rumah sakit [An evaluation of patient safety incident reporting in hospitals]. Jurnal Administrasi Kesehatan Indonesia, 6(2), 83. https://doi.org/10.20473/jaki.v6i2.2018.83-94

Vaismoradi, M., Tella, S., Logan, P. A., Khakurel, J., \& Vizcaya-Moreno, F. (2020). Nurses' adherence to patient safety principles: A systematic review. International Journal of $\begin{array}{lllll}\text { Environmental Research } & & \end{array}$ https://doi.org/10.3390/IJERPH17062028

Vaismoradi, M., Vizcaya-Moreno, F., Jordan, S., Kymre, I. G., \& Kangasniemi, M. (2020). Disclosing and reporting practice errors by nurses in residential long term care settings: A systematic review. Sustainability, 12(7), 2630. https://doi.org/10.3390/SU12072630

van Gerven, E., Bruyneel, L., Panella, M., Euwema, M., Sermeus, W., \& Vanhaecht, K. (2016). Psychological impact and recovery after involvement in a patient safety incident: A repeated measures analysis. BMJ Open, 6(8), 11403. https://doi.org/10.1136/bmjopen-2016-011403

Wanda, M. Y., Nursalam, N., \& Wahyudi, A. S. (2020). Analisis faktor yang mempengaruhi pelaporan insiden keselamatan pasien pada perawat [An analysis of factors influencing patient safety incident reporting among nurses]. Fundamental and Management Nursing Journal, 3(1), 15-24. https://doi.org/10.20473/FMNJ.V3I1.17284

World Health Organization. (2020). Patient safety incident reporting and learning systems: Technical report and guidance. World Health Organization. https://apps.who.int/iris/rest/bitstreams/1303416/retrieve

Younas, A., Rasheed, S. P., Sundus, A., \& Inayat, S. (2020). Nurses' perspectives of self awareness in nursing practice: A descriptive qualitative study. Nursing \& Health Sciences, 22(2), 398405. https://doi.org/10.1111/NHS.12671

Zarea, K., Mohammadi, A., Beiranvand, S., Hassani, F., \& Baraz, S. (2018). Iranian nurses' medication errors: A survey of the types, the causes, and the related factors. International Journal of Africa Nursing Sciences, 8, 112-116. https://doi.org/10.1016/J.IJANS.2018.05.001 